\title{
Research priorities in modeling the transmission risks of H7N9 bird flu
}

\author{
Viroj Wiwanitkit ${ }^{1,2,3^{*}}$, Benyun Shi ${ }^{4}$, Shang Xia ${ }^{4}$, Guo-Jing Yang ${ }^{5}$, Xiao-Nong Zhou ${ }^{6,7,8}$ and Jiming Liu ${ }^{4^{*}}$
}

\begin{abstract}
The epidemic of H7N9 bird flu in eastern China in early 2013 has caused much attention from researchers as well as public health workers. The issue on modeling the transmission risks is very interesting topic. In this article, this issue is debated and discussed in order to promote further researches on prediction and prevention of avian influenza viruses supported by better interdisciplinary datasets from the surveillance and response system.
\end{abstract}

Keywords: H7N9, Bird flu, Transmission, Modeling, Priorities

\section{Multilingual abstracts}

Please see Additional file 1 for translations of the abstract into the six official working languages of the United Nations.

\section{Background}

The epidemic of H7N9 bird flu in eastern China in early 2013 has received much attention from researchers, as well as from public health workers. An article titled "Inferring the potential risks of H7N9 infection by spatiotemporally characterizing bird migration and poultry distribution in eastern China," published in the journal Infectious Diseases of Poverty in 2013 [1], has concluded that risk mapping will provide guidance in active surveillance and control of human H7N9 infections as it would allows corresponding intervention measures to be taken. Some issues regarding the relationship between avian influenza virus (AIV) outbreaks and migration of birds has been raised by Wiwanitkit with emphasis on the prediction methodologies with various data sources, including genetic data of pathogen, immunity, and economic status of humans, as well as ecosystem factors. These issues have been addressed by Shi et al. in a systematic review on the impacts of spatiotemporal migration and contact patterns of bird species in relation to the spread of AIVs, as well as the transmission risks of AIVs to humans.

\footnotetext{
* Correspondence: wviroj@yahoo.com; jiming@Comp.HKBU.Edu.HK ${ }^{1}$ Wiwanitkit House, 10160, Bangkhae, Bangkok, Thailand

${ }^{4}$ Department of Computer Science, Hong Kong Baptist University, Waterloo Road, Kowloon Tong, Hong Kong

Full list of author information is available at the end of the article
}

This response discussion provided detailed information on how to further understand the risks of bird-to-human and human-to-human transmissions by considering various interactive impact factors, and how to better use those impact factors in the surveillance and response system with the aim of preventive actions being supported by better prediction of the transmission risks. This was further echoed by Wiwanitkit who outlines the research priorities of modeling the bird flu epidemic, which could provide guidance to the surveillance and control of AIVs. Therefore, the editor combined all parts of these discussions in one paper, in order to further promote research on the prediction and prevention of AIVs supported by better interdisciplinary datasets from the surveillance and response system. This article is the collation of these discussions.

Viewpoint by viroj wiwanitkit: H7N9 bird flu, bird migration, and poultry distribution

Sir, the recent report by Shi et al. is very interesting [1]. In this predictive model, "bird migration" and "poultry distribution" were assessed for their interrelationship with H7N9 bird flu [1]. Using spatiotemporal risk mapping can be useful for predicting the distribution of H7N9 bird flu. Bird flu is usually the result of a worldwide outbreak due to the migration of birds. However, it is noted that "mixing of bird populations (involving residents and migratory birds) plays an important role in the patterns of disease spread [2]".

An interesting concern is the additional factors that promote the existence of disease. Each year, birds migrate and poultry is widely distributed, but bird flu does not 
break out each year. The effect of migration strategies on the occurrence of the disease is also widely discussed. A report from the USA showed an interesting observation that the prevalence of the virus and its diversity did not differ in birds with different migration strategies [3]. Muzyga et al. reported that outbreaks were related to latitude, but not to migration or habitats [4]. The mismatch between timing of the outbreaks and the migration of birds can also be observed [4]. In fact, the circulation of a virus among a bird population in a specific setting is dynamic and varies on season. A recent study on the avian influenza virus (AVI) among a bird population in Ukraine is a good example which demonstrates the differences between viruses in different seasons [5]. Some previous studies mentioned the importance of immunity to infection in birds in relation to the existence of bird flu. In fact, the seasonal change of immunity is mentioned as an important pathobiology process [6]. Hegemann et al. studied how "immune function in a free-living bird varies over the annual cycle", and found a significant variation in immunity across the annual cycle; as well as that the observation differed between years [7]. Hegemann et al. said that "fluctuating environmental conditions that vary among years [are] likely [to] contribute to the immunological variation [7]". Hence, the occurrence of the virus seems to not be directly related to the migration of birds.

The first problem of emerging bird flu is usually the 'unpredicted' and 'never predicted' sense mutations of influenza virus that trigger cross-species infection. The existence of a virus in a new setting might be proved by a genetic study [8]. However, the detection of mutated virus is usually an observation after the outbreak of the disease $[9,10]$. In fact, there are some surveillance programs on the circulating virus among birds in many countries, such as Bangladesh [11], Vietnam [12], Indonesia [13], Iran [14], as well as others. Based on the data from surveillance, the isolated viruses had a broad range of genotypes indicating variability within genotypes [15]. Of interest, the mutated virus that causes emerging bird flu has never been determined despite surveillance being continuously done prior to the influenza emerging [16]. Due to unpredicted mutation, the new virus occurs and becomes the new problematic human pathogen.

Then, the humans at risk--especially those who have low immunity and live in poor communities--get attacked. This results in the wide spreading of bird flu in humans. The success in disease control at the human phase is not related to poultry control therefore, the data on ecology of birds might be limitedly useful for outbreak management in this particular phase. There are differences in the successes of disease control in different countries despite the same practice of destroying sick birds being implemented [17]. Pavade et al. reported that the countries with high-income economies had fewer and shorter bird flu outbreaks, and the eradication times for controlling the infections were also shorter [17].

In the case of an outbreak, the complexity of bio- and social- aspects of disease distribution should be kept in mind. Economic constraints have many effects on disease control [18]. In a low-income country, the local population might not be able to avoid having poultry in the backyards of their homes as it is their food source [19]. They might have close contact with poultry and its feces, and take the risk to be in contact with it, due to poverty [19]. In addition, the control of the disease cannot be successful if there is no concern for the underlying social geography. A good example is the difficulty in control bird flu in case of transboundary virus circulation among different countries with different political concepts [20]. Developing models based on both biological and socioeconomic data should be considered.

Response by Benyun Shi, Shang Xia, Guo-Jing Yang, Xiao-Nong Zhou, Jiming Liu: Transmission risks of avian influenza viruses through interactive impact factors.

The global spread of avian influenza viruses (AIVs) has always been, and continues to be, a critical threat to humans--and may result in enormous problems for public health. Professor Wiwanitkit has raised some issues concerning: (i) the relationship between the occurrence/timing of outbreaks and migration of birds, (ii) the emergence of a new virus due to unpredicted mutations, (iii) the risks humans with low immunity and low incomes face, and (iv) the impact of some biological and sociological factors to the existence of AIVs. All these issues touch the complex nature of bird flu epidemic, surveillance, and control. We would like to offer the following points for clarification, as well as for further discussion.

Generally speaking, the global spread of AIVs is a complex process which may depend on many factors, such as the location and timing of virus emergence, host species infected, viral characteristics and pathogenicity, and unforeseen stochastic events (e.g., rare cold weather) [21]. In light of the issues raised by Professor Wiwanitkit concerning the roles of the mixing of bird populations and the complexity of biological and social aspects of disease distribution, we would like to put forward the following in-depth discussion about the impacts of bird migration on the spread of AIVs, as well as the transmission risks of AIVs to humans. Specifically, we would like to emphasize three fundamental issues, namely, (i) predicting the spread of a complete (unreassorted whole genome) AIV by identifying the migration flyways of different bird species, (ii) assessing the potential emergence of new AIVs via genetic reassortment by quantifying the contact patterns of birds sharing habitats/stopovers, and (iii) understanding the risks of bird-to-human and humanto-human transmissions by considering various interactive 
impact factors, such as biological, demographical, socioeconomic, and environmental.

Regarding the first issue, evidence has indicated that migratory birds contribute, in part, to the spatial epidemic spread of AIVs, such as the worldwide H5N1 outbreaks $[22,23]$. At a global/coarse scale, the intercontinental flyways of migratory birds (e.g., the East Asian/Australia flyway), and flyways within a continent (e.g., Atlantic, Central, Mississippi, and Pacific flyways within North America [24]) have been assessed using bird banding, satellite tracking, and other techniques. To a certain extent, such pathways can help assess the introduction pathways of an AIV between continents/countries [21]. We would argue that the bird migration patterns on a finer scale (e.g., within a country/province) could be helpful for predicting the spread of a complete AIV during a short time period, like the H7N9 outbreak in eastern China from February to May 2013 [1]. Moreover, since the spread of AIVs depends on the host species that have been infected, it becomes extremely important for us to identify the flyways of individual bird species, which may exhibit heterogeneous spatiotemporal patterns. By taking into consideration both the migration of infected bird species and the possible inter-species transmissions of the virus (e.g., due to the overlapping of flyways), we will be able to quickly respond to a potential outbreak based on the location and timing of its emergence.

With respect to the second issue, migratory birds, as a natural reservoir, play important roles in the emergence of new AIVs via genetic reassortment. Reassortment can only occur when individuals are co-infected by multiple low pathogenic AIV strains. For example, recent studies have shown that the reassortment of at least four origins contributes to the emergence of the avian influenza H7N9. They are: East Asian duck origin for hemagglutinin (HA), European wild duck for neuraminidase (NA), and at least two H9N2 chicken viruses for the internal genes [25,26]. Phylogenetic analysis on the historically recorded AIVs indicates that genetic reassortment is most likely the cause of divergent gene pools of AIVs across large geographic scales [27]. Moreover, evidence has shown that mixed lineage viruses are usually found in locations where migratory flyways overlap. In this case, to assess the location and timing of the potential emergence of new AIVs, it would be helpful for us to identify migratory hotspots by quantifying the contact patterns of bird species (involving residents and migratory birds) sharing habitats and stopovers [28]. By doing so, active surveillance on the frequency of reassortment can be effectively implemented so as to prevent the outbreak of new highly pathogenic AIVs (HPAIVs) [29-31].

At present, a large quantity of observation data can be collected using various methods (e.g., bird banding and satellite tracking $[5,32])$ to assess the bird migration and contact patterns. For example, the United States Geological Survey (USGS) has documented more than ten thousands movements of aquatic birds between 1920 and 2013 [33]. The Cornell Lab of Ornithology has conducted a citizen science project (i.e., eBird), which has collected millions of bird observations--and the general public collated and presented the information on the location, data, species and other information throughout North America through the eBird Web application [34]. In China, similar bird observation data have been collected by the China Bird Watching Network, which is maintained by the Hong Kong Bird Watching Society [35]. All these data can help assess the migration patterns of a particular bird species and the contact patterns between different species on a finer scale. For example, machine-learning methods have been adopted to estimate the bird migration patterns from eBird observation data [36,37]. Spatiotemporal data analysis, such as exploratory models $[38,39]$ and spatial clustering [40-42], have also been used to identify hotspots and further assess the bird contact patterns. The wellelaborated bird migration and contact patterns will in turn contribute to our better understanding of both the spread of the disease at the global level and the virus evolution at the genetic level.

Even for the aforementioned two issues considering only the prevalence of AIVs in bird species, experimental studies have shown that the susceptibility to infection varies not only by virus subtypes, but also by the species exposed $[43,44]$.

As for the third issue concerning the bird-to-human and human-to-human transmissions, there is potential for the spread of AIVs to become more complex, and subject to a series of interactive biological, demographical, socioeconomic, and environmental factors. As commented on by Professor Wiwanitkit, unpredicted mutations may change viral characteristics and pathogenicity, as well as the mode of transmission. For example, it has been verified recently that one strain of the $\mathrm{H} 7 \mathrm{~N} 9$ virus appears to spread easily through the air between ferrets due to mutations, which spotlights the risks of mammal-to-mammal spread [45]. Meanwhile, age-specific and location-specific human immunities to AIVs, which may be highly related to historical exposures of the host population, are also of critical importance for the spread of the disease [46-49]. Once the human-to-human transmission is confirmed, more impact factors should be carefully considered, such as human mobility and contact patterns [50,51], and social influence [52-54]. We agree with Professor Wiwanitkit in this regard and believe that it would be essential for us to study the spread of AIVs from a novel, complex systems perspective.

In summary, quantifying bird migration and contact patterns on a finer scale will contribute to both the prediction of the spread of the disease at the global level and the 
assessment of potential reassortment of AIVs at the genetic level. Accordingly, the results will offer public health managers new insights into (i) how to implement active surveillance before the outbreak of an AIV, and (ii) how to quickly respond to the outbreak of an AIV at the beginning of its spread. To further carry out systematic modeling of the global spread of bird flu and hence understand the impacts of interactive factors across different scales, interdisciplinary research efforts and international collaboration will be extremely important.

\section{Response by viroj wiwanitkit: research priorities of modeling transmission risks of bird flu}

Prof Liu et al. gave very useful information and discussions on the "transmission risks of avian influenza viruses through interactive impact factors." In conclusion, Prof Liu et al. mentioned the usefulness of "quantifying bird migration and contact patterns on a finer scale" in two main ways: (a) an alternative way for active surveillance of the possible outbreak of AIVs, and as (b) a tool or a guidance for the early-phase predictions of an outbreak. Without a doubt, the best model has to be further developed. A model which includes the impacts of interactive factors across different scales is our aim.

As Prof Liu et al. noted, interdisciplinary work and international collaboration is needed for the success in developing such a model that can be useful worldwide. In fact, this is the concern that has been raised by some experts [55-57]. For example, the group of El-Zoghby et al. in Egypt called for "global collaboration" to set an effective surveillance system to fight AIVs [55]. Abdelwhab et al. also interestingly mentioned that there could be no success in controlling the situation of an AIV outbreak in a nation, which was in this case Egypt, without international collaboration [56]. In fact, the attempt to form the collaboration has already been made. A good example is the "The 2008 FAO-OIE-WHO Joint Technical Consultation on Avian Influenza at the Human Animal Interface." [58,59].

There is no doubt that there is still a long way to go, and many further efforts and challenges ahead for medical scientists and analytics researchers. It is necessary to plan for success to be achieved. At present, the research priorities for the current situation should focus on the following:

A. The collection of data from each setting is very important. Since the model has to be based on data, more data mean a more accurate model. To get the best data in each setting, interdisciplinary teams should work to collect the data in a holistic way, covering biological, physical, social, and humanistic facets [60]. A good example is the work published by Vanthemsche et al. [61].
B. Bridging or fusing data from different sources to form the final "homogenized" data has to be done. This is the first step to developing a perfect, systematic model of the global spread of bird flu. A good example is the attempt by Breton et al. to use an in silico technique for manipulating international grid data for the integration of existing data sources towards a global surveillance network [62].

C. An effective predictive model has to be developed. The important key for success of the derived model for prediction of the situation is its sensitivity to correspond to the dynamic nature of an AIV outbreak. The use of advanced mathematical modeling and innovative informatics techniques might be a way to predict "risk", not "existence", for the occurrence of an outbreak early. To correspond to a new emerging influenza, the model that can perform an immediate identification of an impending epidemic and pandemic strains can be hugely successful in combating influenza [63].

Finally, it should be emphasized that the model, and the surveillance and response system, should be continuously operated and improved. The sustainability is very important.

\section{List of research priorities}

- Data Collection: A rich set of relevant data across different scales (e.g., biological, demographical, socioeconomic, and environmental data) should be continuously collected, carefully maintained, and publicly shared through an interdisciplinary team effort.

- Data Processing: Advanced data analytics technologies (e.g., machine learning, data mining, and spatiotemporal exploratory methods) should be developed to process the available large-scale, sparse, or even biased datasets.

- Complex Systems Modeling: A systematic modeling approach, which bridges data from various sources at different scales, should be developed to best understand the transmission risks of AIVs to humans from a complex systems' perspective.

- Risk Prediction: Prediction models with both shortterm and long-term estimations for bird-to-human and human-to-human transmission risks should be developed and deployed so as to offer public health authorities and practitioners with new insights into, as well as new tools for, both active surveillance and infection control of AIVs. 
- Simulation and Optimization: Advanced computer simulation tools and optimization approaches should be developed and deployed to (i) envision the real-world situations for the potential spread of AIVs, and (ii) provide optimal decision-making strategies for public health authorities and practitioners to quickly respond to the emergence of AIV outbreaks. All above-mentioned systems should be continuously operated and improved based on the data from dynamically changing environments.

\section{Additional file}

Additional file 1: Multilingual abstracts in the six official working languages of the United Nations.

\section{Competing interests}

The authors declare that they have no competing interests.

\section{Authors' contributions}

WW draft the Part 2 and Part 4, BS and JL draft the Part 3 and Box 1. XNZ draft the Part 1. WW, BS, SX, GJY, XNZ, JL improved the whole manuscript and approved the final version.

\section{Author details \\ 'Wiwanitkit House, 10160, Bangkhae, Bangkok, Thailand. ${ }^{2}$ Hainan Medical University, Haikou 570100, China. ${ }^{3}$ Faculty of Medicine, University of Nis, Nis 18000, Serbia. ${ }^{4}$ Department of Computer Science, Hong Kong Baptist University, Waterloo Road, Kowloon Tong, Hong Kong. ${ }^{5}$ The Jockey Club School of Public Health and Primary Care, Chinese University of Hong Kong, New Territories, Hong Kong. ${ }^{6}$ National Institute of Parasitic Diseases, Chinese Center for Disease Control and Prevention, Shanghai 200025, China. ${ }^{7}$ Key Laboratory of Parasite and Vector Biology, MOH, Shanghai 200025, China. ${ }^{8}$ WHO Collaborating Center for Malaria, Schistosomiasis and Filariasis, Shanghai 200025, China.}

Received: 17 July 2013 Accepted: 6 August 2013 Published: 8 August 2013

\section{References}

1. Shi B, Xia S, Yang GJ, Zhou XN, Liu J: Inferring the potential risks of H7N9 infection by spatiotemporally characterizing bird migration and poultry distribution in eastern China. Infect Dis Poverty 2013, 2(1):8.

2. Ríos-Soto KR, Song B, Castillo-Chavez C: Epidemic spread of influenza viruses: The impact of transient populations on disease dynamics. Math Biosci Eng 2011, 8(1):199-222.

3. Dugan VG: A robust tool highlights the influence of bird migration on influenza A virus evolution. Mol Ecol 2012, 21(24):5905-5907.

4. Muzyka D, Pantin-Jackwood M, Spackman E, Stegniy B, Rula O, Shutchenko $P$ : Avian influenza virus wild bird surveillance in the Azov and Black Sea regions of Ukraine (2010-2011). Avian Dis 2012, 56(4 Suppl):1010-1016.

5. Takekawa JY, Newman SH, Xiao X, Prosser DJ, Spragens KA, Palm EC, Yan B, Li T, Lei F, Zhao D, Douglas DC, Muzaffar SB, Ji W: Migration of waterfowl in the East Asian flyway and spatial relationship to HPAI H5N1 outbreaks. Avian Dis 2010, 54(1 Suppl):466-476.

6. Nelson RJ, Demas GE: Seasonal changes in immune function. Q Rev Biol 1996, 71(4):511-548.

7. Hegemann A, Matson KD, Both C, Tieleman BI: Immune function in a free-living bird varies over the annual cycle, but seasonal patterns differ between years. Oecologia 2012, 170(3):605-618.

8. Prosser DJ, Cui P, Takekawa JY, Tang M, Hou Y, Collins BM, Yan B, Hill NJ, Li T, Li Y, Lei F, Guo S, Xing Z, He Y, Zhou Y, Douglas DC, Perry WM, Newman SH: Wild bird migration across the Qinghai-Tibetan plateau: a transmission route for highly pathogenic H5N1. PLOS One 2011, 6(3):e17622.
9. Gilbert M, Newman SH, Takekawa JY, Loth L, Biradar C, Prosser DJ, Balachandran S, Subba Rao MV, Mundkur T, Yan B, Xing Z, Hou Y, Batbayar N, Natsagdorj T, Hogerwerf L, Slingenbergh J, Xiao X: Flying over an infected landscape: distribution of highly pathogenic avian influenza $\mathrm{H} 5 \mathrm{~N} 1$ risk in South Asia and satellite tracking of wild waterfowl. Ecohealth 2010, 7(4):448-458.

10. Newman SH, Hill NJ, Spragens KA, Janies D, Voronkin IO, Prosser DJ, Yan B, Lei F, Batbayar N, Natsagdorj T, Bishop CM, Butler PJ, Wikelski M, Balachandran S, Mundkur T, Douglas DC, Takekawa JY: Eco-virological approach for assessing the role of wild birds in the spread of avian influenza H5N1 along the Central Asian Flyway. PLoS One 2012, 7(2):e30636.

11. Ahmed SS, Themudo GE, Christensen JP, Biswas PK, Giasuddin M, Samad MA, Toft N, Ersbøll AK: Molecular epidemiology of circulating highly pathogenic avian influenza (H5N1) virus in chickens, in Bangladesh, 2007-2010. Vaccine 2012, 30(51):7381-7390.

12. Klimov A, Donis RO, Lindstrom SE, York IA, Shu B, Loughlin R, Ferdinand K, Vui DT, Simpson N, Huong NT, Balish A, Dang NH, Jones J, Hoa Do T, Nguyen T, Rivailler P, Davis CT: Evolution of highly pathogenic avian influenza (H5N1) virus populations in Vietnam between 2007 and 2010. Virology 2012, 432(2):405-416.

13. Lam $\Pi$, Hon CC, Lemey P, Pybus OG, Shi M, Tun HM, Li J, Jiang J, Holmes EC, Leung FC: Phylodynamics of H5N1 avian influenza virus in Indonesia. Mol Ecol 2012, 21(12):3062-3077.

14. Majidzadeh K, Karimi V, Soleimanidor M, Estabragh AS, Barin A, Langeroudi AG: Phylogenetic study on nonstructural (NS) gene of H9N2 isolated from broilers in Iran during 1998-2007. Pak J Biol Sci 2011, 14(17):838-843.

15. Sims LD, Domenech J, Benigno C, Kahn S, Kamata A, Lubroth J, Martin V, Roeder P: Origin and evolution of highly pathogenic $\mathrm{H} 5 \mathrm{~N} 1$ avian influenza in Asia. Vet Rec 2005, 157(6):159-164.

16. Jadhao SJ, Nguyen DC, Uyeki TM, Shaw M, Maines T, Rowe T, Smith C, Huynh LP, Nghiem HK, Nguyen DH, Nguyen HK, Nguyen HH, Hoang LT, Nguyen T, Phuong LS, Klimov A, Tumpey TM, Cox NJ, Donis RO, Matsuoka Y, Katz JM: Genetic analysis of avian influenza A viruses isolated from domestic waterfowl in live-bird markets of Hanoi, Vietnam, preceding fatal H5N1 human infections in 2004. Arch Virol 2009, 154(8):1249-1261.

17. Pavade G, Awada L, Hamilton K, Swayne DE: The influence of economic indicators, poultry density and the performance of veterinary services on the control of high-pathogenicity avian influenza in poultry. Rev Sci Tech 2011, 30(3):661-671.

18. Capua I, Cattoli G: Prevention and control of highly pathogenic avian influenza with particular reference to H5N1. Virus Res 2013. pii: S01681702(13)00116-0. doi: 10.1016/j.virusres.2013.04.002. [Epub ahead of print].

19. Sultana R, Nahar N, Rimi NA, Azad S, Islam MS, Gurley ES, Luby SP: Backyard poultry raising in Bangladesh: a valued resource for the villagers and a setting for zoonotic transmission of avian influenza. A qualitative study. Rural Remote Health 2012, 12:1927.

20. Fournié G, Guitian J, Desvaux S, Cuong VC, Dung Do H, Pfeiffer DU, Mangtani P, Ghani AC: Interventions for avian influenza A (H5N1) risk management in live bird market networks. Proc Natl Acad Sci U S A 2013, 110(22):9177-82

21. Miller RS, Steven JS, Judy EA, Emi KS: Assessment of introduction pathway for novel avian influenza virus into North America by wild birds from Eurasia. Fort Collins: USDA:APHIS:VS: Center for Epidemology and Animal Health; 2013.

22. Kilpatrick AM, Chmura AA, Gibbons DW, Fleischer RC, Marra PP, Daszak P: Predicting the global spread of H5N1 avian influenza. Proc Natl Acad Sci 2006, 103(51):19368-19373.

23. Liang L, Xu B, Chen Y, Liu Y, Cao W, Fang L, Feng L, Goodchild MF, Gong P: Combining spatial-temporal and phylogenetic analysis approaches for improved understanding on global H5N1 transmission. PLOS One 2010, 5(10):e13575.

24. Migratory Bird Program. Source: http://www.fws.gov/migratorybirds/flyways.html.

25. Liu D, Shi W, Shi Y, Wang D, Xiao H, Li W, Bi Y, et al: Origin and diversity of novel avian influenza A H7N9 viruses causing human infection: phylogenetic, structural, and coalescent analyses. Lancet 2013, 381(9881):1926-1932.

26. Gao R, Cao B, Hu Y, Feng Z, Wang D, Hu W, Chen J, et al: Human infection with a novel avian-origin influenza A (H7N9) virus. N Engl J Med 2013, 368(20):1888-1897.

27. Widjaja L, Krauss SL, Webby RJ, Xie T, Webster RG: Matrix gene of influenza a viruses isolated from wild aquatic birds: ecology and emergence of influenza a viruses. J Virol 2004, 78(16):8771-8779. 
28. Fuller TL, Gilbert M, Martin V, Cappelle J, Hosseini P, Njabo KY, Aziz SA, Xiao X, Daszak $P$, Smith TB: Predicting hotspots for influenza virus reassortment. Emerging Infect Dis 2013, 19(4):581-588.

29. Pearce JM, Reeves AB, Ramey AM, Hupp JW, Ip HS, Bertram M, Petrula MJ, et al: Interspecific exchange of avian influenza virus genes in Alaska: the influence of trans-hemispheric migratory tendency and breeding ground sympatry. Mol Ecol 2011, 20(5):1015-1025.

30. Pearce JM, Ramey AM, Flint PL, Koehler AV, Fleskes JP, Franson JC, Hall JS, Derksen DV, Ip HS: Avian influenza at both ends of a migratory flyway: characterizing viral genomic diversity to optimize surveillance plans for North America. Evolutionary App/ 2009, 2(4):457-468.

31. Dugan VG, Chen R, Spiro DJ, Sengamalay N, Zaborsky J, Ghedin E, Nolting J, et al: The evolutionary genetics and emergence of avian influenza viruses in wild birds. PLoS Pathog 2008, 4(5):e1000076.

32. Zhou Y, Pan W, Li J, Wang W, Shao J, Wu L, Yang Q, Yan B: Bird Flu Outbreak Prediction via Satellite Tracking. IEEE Intell Syst 2013, 1:1.

33. USGS: North American bird banding and band encounter data set. Laurel, MD: United States Geologic Survey Bird Banding Laboratory, Patuxenet Wildlife Research Center; 2011.

34. Welcome to eBird. Source: http://ebird.org.

35. China Bird Watching Network Website. Source: http://www.chinabirdnet.org/.

36. Elmohamed M, Kozen D, Sheldon DR: Collective inference on Markov models for modeling bird migration. In Advances in Neural Information Processing Systems; 2007:1321-1328.

37. Wu X, Kumar A, Sheldon D, Zilberstein S: Parameter Learning for Latent Network Diffusion. In Proceedings of the Twenty-Third International Joint Conference on Artificial Intelligence. Beijing: los Press; 2013.

38. Fink D, Hochachka WM, Zuckerberg B, Winkler DW, Shaby B, Munson MA, Hooker G, Riedewald M, Sheldon D, Kelling S: Spatiotemporal exploratory models for broad-scale survey data. Ecol App/ 2010, 20(8):2131-2147.

39. Gelfand AE, Diggle PJ, Fuentes M, Guttorp P: Handbook of spatial statistics. Chapman and hall/CRC handbooks of modern statistical methods. New York CRC Press; 2010

40. Kulldorff M: A spatial scan statistic. Commun Stat-Theory Methods 1997, 26(6):1481-1496.

41. Ester M, Kriegel HP, Sander J, Xu X: A density-based algorithm for discovering clusters in large spatial databases with noise. In KDD 1996, 96:226-231.

42. Daszykowski M, Walczak B, Massart DL: Looking for natural patterns in data: Part 1. Density-based approach. Chemom Intell Lab Syst 2001, 56(2):83-92.

43. Hall JS, Franson JC, Gill RE, Meteyer CU, Teslaa JL, et al: Experimental challenge and pathology of highly pathogenic avian influenza virus H5N1 in dunlin (Calidris alpina), an intercontinental migrant shorebird species. Influenza Other Respi Viruses 2011, 5(5):365-372.

44. Hall JS, Krauss S, Franson JC, TeSlaa JL, Nashold SW, Stallknecht DE, Webby RJ, Webster RG: Avian influenza in shorebirds: experimental infection of ruddy turnstones (Arenaria interpres) with avian influenza virus. Influenza Other Respi Viruses 2013, 7(1):85-92.

45. H7N9 Bird Flu Virus Capable of Airborne Transmission. Source: http:// esciencenews.com/sources/live.science/2013/07/18/h7n9.bird.flu.virus. capable.airborne.transmission; http://esciencenews.com/sources/science. now/2013/07/18/can.dangerous.bird.flu.virus.fly.between.humans.

46. Dudley JP: Age-specific infection and death rates for human A (H5N1) avian influenza in Egypt. Eurosurveillance 2009, 14:18.

47. Fisman DN, Savage R, Gubbay J, Achonu C, Akwar H, Farrell DJ, Crowcroft NS, Jackson P: Older age and a reduced likelihood of $2009 \mathrm{H} 1 \mathrm{~N} 1$ virus infection. N Engl J Med 2009, 361(20):2000-2001.

48. Karageorgopoulos DE, Vouloumanou EK, Korbila IP, Kapaskelis A, Falagas ME: Age distribution of cases of 2009 (H1N1) pandemic influenza in comparison with seasonal influenza. PLoS One 2011, 6(7):e21690.

49. Mostaço-Guidolin LC, Towers SM, Buckeridge DL, Moghadas SM: Age Distribution of Infection and Hospitalization among Canadian First Nations Populations During the 2009 H1N1 Pandemic. Am J Public Health 2013, 103(2):e39-e44.

50. Medlock J, Galvani AP: Optimizing influenza vaccine distribution. Science 2009, 325(5948):1705-1708.

51. Xia S, Liu J, Cheung W: Identifying the Relative Priorities of Subpopulations for Containing Infectious Disease Spread. PLoS One 2013, 8(6):e65271.

52. Galvani AP, Reluga TC, Chapman GB: Long-standing influenza vaccination policy is in accord with individual self-interest but not with the utilitarian optimum. Proc Nat Acad Sci 2007 2007, 104(13):5692-5697.
53. Xia S, Liu J: A Computational Approach to Characterizing the Impact of Social Influence on Individuals' Vaccination Decision Making. PLoS One 2013, 8(4):e60373.

54. Lau JTF, Yeung NCY, Choi KC, Cheng MYM, Tsui HY, Griffiths S: Acceptability of $A / H 1 N 1$ vaccination during pandemic phase of influenza $A / H 1 N 1$ in Hong Kong: population based cross sectional survey. Br Med J 2009, 339:b4164.

55. El-Zoghby EF, Aly MM, Nasef SA, Hassan MK, Arafa AS, Selim AA, Kholousy SG, Kilany WH, Safwat M, Abdelwhab EM, Hafez HM: Surveillance on $\mathrm{A} / \mathrm{H} 5 \mathrm{~N} 1$ virus in domestic poultry and wild birds in Egypt. Virol J 2013, 10:203.

56. Abdelwhab EM, Hafez HM: An overview of the epidemic of highly pathogenic H5N1 avian influenza virus in Egypt: epidemiology and control challenges. Epidemiol Infect 2011, 139(5):647-57.

57. Kudo K, Manabe T, Izumi S, Takasaki J: Trends in and challenges for highly pathogenic avian influenza A (H5N1). Nihon Rinsho 2010, 68(9):1736-42.

58. Anderson T, Capua I, Dauphin G, Donis R, Fouchier R, Mumford E, Peiris M Swayne D, Thiermann A: FAO-OIE-WHO Joint Technical Consultation on Avian Influenza at the Human-Animal Interface. Influenza Other Respi Viruses 2010, 4(Suppl 1):1-29.

59. Dauphin G, Hamilton K, Kim LM, Choudhury B, Capua I, Edwards S: Main achievements of the World Organisation for Animal Health/United Nations Food and Agriculture Organization network on animal influenza. Avian Dis 2010, 54(1 Suppl):380-3.

60. Khan AU: Bird Flu: a recent threat to human health. Bioinformation 2006 1(4):132.

61. Vanthemsche P, Robesyn E, Claeys H, Matthijs B, Snacken R, Maes S, Jooris I, Reynders D, Guilmin P, Janssens W, Moriaux R, Haucotte G: Influenza: an example of interdisciplinary analysis of risks. Bull Mem Acad R Med Belg 2006, 161(5):246-58.

62. Breton V, da Costa AL, de Vlieger P, Kim YM, Maigne L, Reuillon R, Sarramia D, Truong NH, Nguyen HQ, Kim D, Wu YT: Innovative in silico approaches to address avian flu using grid technology. Infect Disord Drug Targets 2009, 9(3):358-65.

63. Shapshak P, Chiappelli F, Somboonwit C, Sinnott J: The influenza pandemic of 2009: lessons and implications. Mol Diagn Ther 2011, 15(2):63-81.

doi:10.1186/2049-9957-2-17

Cite this article as: Wiwanitkit et al:: Research priorities in modeling the transmission risks of H7N9 bird flu. Infectious Diseases of poverty 2013 2:17.

\section{Submit your next manuscript to BioMed Central and take full advantage of:}

- Convenient online submission

- Thorough peer review

- No space constraints or color figure charges

- Immediate publication on acceptance

- Inclusion in PubMed, CAS, Scopus and Google Scholar

- Research which is freely available for redistribution 